\title{
Uso de Bovinos e de Ovinos como Agentes de Controle da Vegetação Nativa sob Três Populações de Eucalipto ${ }^{1}$
}

\author{
Alexandre Costa Varella², João Carlos de Saibro ${ }^{3}$
}

\begin{abstract}
RESUMO - O objetivo deste trabalho foi avaliar cinco sistemas de controle da vegetação nativa e os danos provocados por bovinos e ovinos em três populações de eucalipto. O delineamento experimental foi em parcelas subdivididas, com dois blocos completos. Os tratamentos foram: a) três densidades de Eucalyptus saligna Smith. (204, 400 e 816 árvores/ha) nas parcelas principais e b) cinco sistemas de controle da vegetação nativa (sem controle, herbicida pré-emergente, herbicidas pré e pós-emergentes, pastejo com bovinos e com ovinos) nas subparcelas. O pastejo com bovinos ou ovinos foi mais eficiente na redução da vegetação nativa que nos demais tratamentos. Os bovinos danificaram mais as árvores que os ovinos. Existe estreita relação entre a altura das mudas de eucalipto e os danos causados pelos bovinos e ovinos no momento da introdução destes animais no sub-bosque.
\end{abstract}

Palavras-chave: bovinos, competição, Eucalyptus saligna Smith., ovinos, sistema silvopastoril

\section{Use of Cattle and Sheep as Agents to Control the Growth of Native Vegetation underneath of Three Eucalyptus Populations}

\begin{abstract}
The objective of this work was to evaluate five control systems of native vegetation and the damages caused by cattle and sheep to trees of three eucalyptus populations. A split-plot experimental design in two randomized complete blocks was used. Treatments were a) three populations of Eucalyptus saligna Smith. (204, 400 and 816 plants/ha) as the main plots; b) five control systems of the native vegetation (without control, pre-emergent herbicide, pre and post-emergent herbicides, cattle grazing or sheep grazing) as subplots. The cattle and sheep grazing were the most efficient than any other treatments. The cattle caused more damage to the trees than sheep did. There is a close relation between tree height and damages caused by cattle and sheep at the moment of the introduction of these animals in the underneath forest.
\end{abstract}

Key Words: cattle, competition, Eucalyptus saligna Smith, sheep, silvopastoral system

\section{Introdução}

Grande parte das florestas de eucalipto localizadas no Estado do Rio Grande do Sul é plantada sobre a pastagem nativa, com a qual se estabelece competição intensa por água, luz e nutrientes. O controle desta vegetação herbácea no ano da implantação da floresta é um dos mais graves problemas encontrados nos atuais sistemas de cultivo utilizados no estado. $\mathrm{O}$ alto custo de aplicação de herbicidas ou de contratação da mão-de-obra, a dificuldade de utilização do controle químico de invasoras em áreas mais declivosas e alagadiças e os riscos de contaminação ambiental com o uso de herbicidas levaram a introdução de bovinos ou de ovinos em florestas, caracterizando um sistema silvopastoril. Os sistemas silvopastoris, além de possibilitarem o controle biológico das espécies daninhas à floresta, também permitem a obtenção de rendimentos financeiros adicionais e antecipados pela comercialização do produto animal, oferecem permanente cobertura vegetal ao solo, reduzem os riscos de incêndio no interior da floresta, entre outras vantagens (VEIGA e SERRÃO, 1990; COUTO et al., 1994).

Os argumentos desfavoráveis à utilização de animais como ferramentas de controle da vegetação nativa no ano do estabelecimento de florestas comerciais baseiam-se fundamentalmente nos danos que podem ser causados às árvores. Este prejuízo pode se verificar por meio de danos mecânicos (pisoteio de mudas e quebra de ramos), mastigação de folhas e

${ }^{1}$ Parte da Dissertação de Mestrado do primeiro autor apresentada ào Departamento de Plantas Forrageiras e Agrometeorologia da Faculdade de Agronomia/UFRGS.

2 Eng. Agr., M.Sc. em Zootecnia, área de Plantas Forrageiras, Rua Professor Fitzgerald, n 58, CEP 90470-160 Porto Alegre, RS, E-mail: varella@pro.via-rs.com.br.

${ }^{3}$ Eng. Agr., Ph.D., Faculdade de Agronomia/UFRGS, Av. Bento Gonçalves, 7712, Caixa Postal 776, CEP 90012-970 Porto Alegre, RS. Bolsista do CNPq. 
efeito indireto do pisoteio animal no grau de compactação do solo. Por outro lado, POPAY e FIELD (1996) afirmam que os danos provocados pelos animais às árvores dependem principalmente de três fatores: a qualidade do substrato forrageiro do sub-bosque disponível aos animais, a palatabilidade do tecido foliar da espécie arbórea utilizada aos animais e a experiência prévia dos animais em pastejar sob ecossistemas florestais (HAINES et al., 1994). Além disso, produtores e empresas florestadoras freqüentemente apontam a densidade arbórea como outro fator que influencia o nível de danos às árvores provocados pelos animais. Segundo esses autores, espaçamentos arbóreos menores tendem a diminuir o grau de dano causado pelos animais às árvores.

Com o objetivo de estudar o uso de bovinos ou ovinos como agentes de controle da vegetação nativa no ano do estabelecimento de uma floresta e os danos provocados por estes animais às árvores, foi estabelecido um experimento, na região da Depressão Central do Rio Grande do Sul, utilizando diferentes densidades de Eucalyptus saligna Smith., clone 175, e cinco sistemas de controle da vegetação nativa do sub-bosque.

\section{Material e Métodos}

O experimento foi desenvolvido na Estação Experimental Agronômica da Universidade Federal do Rio Grande do Sul (EEA/UFRGS), em Eldorado do Sul, RS, região fisiográfica da Depressão Central do Estado. O clima da região é considerado subtropical úmido de verão quente (Cfa, segundo classificação de Köppen). A área total do experimento foi de aproximadamente quatro hectares e cada subparcela de $1300 \mathrm{~m}^{2}$. O solo, ácido, com baixos teores de fósforo e alumínio trocável, é classificado como Plintossolo e foi corrigido com $4 \mathrm{t} / \mathrm{ha}$ de calcário dolomítico aplicado em novembro de 1992. A pastagem nativa era composta predominantemente por Axonopus affinis Chase (Grama Sempre-Verde), Paspalum notatum F (Grama Forquilha) e Desmodium incanum DC (Pega-Pega), com freqüências de 28,13 e $8 \%$, respectivamente.

O delineamento experimental utilizado foi o de parcelas subdivididas em blocos completos, formando fatorial $3 \times 5$, com duas repetições. Os tratamentos consistiram de: a) três densidades de Eucalyptus saligna Smith. clone 175 (204, 400 e 816 plantas/ha e espaçamentos de 7 × 7,5 x 5 e 3,5 x 3,5 m, respectivamente) nas parcelas principais; b) cinco sistemas de controle da vegetação nativa (SC) nas subparcelas: SC1-Sem controle(Testemunha); SC2Uso de herbicida pré-emergente (Oxyfluorfen $240 \mathrm{~g}$ / 1) aplicado logo após o plantio; SC3-Uso de herbicida pré e pós-emergente (Oxyfluorfen 240 g/l e Glyphosate $520 \mathrm{~g} / \mathrm{l})$ aplicados após o plantio e 120 dias após a primeira aplicação, respectivamente; SC4-Uso de herbicida pré-emergente (Oxyfluorfen $240 \mathrm{~g} / 1$ ) logo após o plantio e 120 dias após pastejo com bovinos; e SC5-Uso de herbicida pré-emergente (Oxyfluorfen $240 \mathrm{~g} / \mathrm{l}) \operatorname{logo}$ após o plantio e 120 dias após pastejo com ovinos. Os animais foram introduzidos na área experimental sete meses após o plantio das mudas de eucalipto. O pastejo foi realizado seqüencialmente por repetição. Os bovinos (peso vivo médio de $180 \mathrm{~kg}$ / animal e altura média de $108 \mathrm{~cm}$ ) e os ovinos (peso vivo médio de $50 \mathrm{~kg} /$ animal e altura média de $68 \mathrm{~cm}$ ) foram submetidos à pressão de pastejo de $6 \%$, ou seja, $6 \mathrm{~kg}$ de matéria seca de forragem para cada 100 $\mathrm{kg}$ de peso vivo animal por hectare ao dia. Os animais foram mantidos na área entre seis e oito dias, quando o resíduo de forragem atingiu os níveis conhecidos para oferta de forragem nativa de $6 \%$. As seguintes avaliações foram realizadas no período de abril a agosto de 1996: a) disponibilidade de matéria seca total nas linhas e entrelinhas da floresta; b) altura das árvores antes, logo após e três meses após o pastejo; c) danos provocados às árvores estimados através da seguinte escala de pontuação: A (sem dano), B1 (dano leve, atingindo os ramos inferiores), B2 (dano médio, nos ramos da porção média da árvore), B3 (dano severo, atingindo os ramos superiores), B4 (dano muito severo, nos ramos superiores e na extremidade do caule) e B5 (dano máximo, atingindo todos os ramos da árvore); d) redução de área foliar (RAF em \%) causada pelos animais às árvores (consumo de folhas).

O estabelecimento das mudas de eucalipto seguiu os critérios da empresa Riocell S.A. O preparo do solo foi realizado apenas na faixa de plantio, através de subsolagem seguida de dupla gradagem superficial. O plantio das mudas ocorreu em outubro de 1995 e a adubação foi calculada em função da Recomendação Oficial dos Laboratórios de Análises de Solos (ROLAS) e da análise de solo da área. As análises estatísticas dos dados foram feitas por intermédio da análise de variância e o teste de comparação das médias, do teste $\mathrm{F}$ de contrastes ortogonais, a $5 \%$ de probabilidade.

\section{Resultados e Discussão}

O pastejo rápido e intenso, realizado pelos bovinos ou ovinos, demonstrou ser tão eficiente quanto os 
32 Rev. bras. zootec.

sistemas de controle químico da vegetação nativa do sub-bosque. Apesar de a área ter ficado diferida desde o plantio da floresta, durante os meses de verão e de outono, provocando acúmulo de biomassa e redução da qualidade nutritiva da vegetação nativa sob as mudas de eucalipto, os animais reduziram significativamente a disponibilidade total de matéria seca (DMST) nas linhas e entrelinhas da floresta. A Tabela 1 mostra que, tanto na entrelinha quanto na faixa de plantio do eucalipto, em que a competição com a vegetação nativa é mais intensa no ano do estabelecimento da floresta, os bovinos e os ovinos diminuíram significativamente a DMST em relação à testemunha e aos demais sistemas de controle. $\mathrm{Na}$ linha de plantio das árvores, o sistema de controle da vegetação nativa com herbicida pré e pós-emergente (SC3), comumente utilizado pelos produtores e pelas empresas florestadoras, foi mais eficiente que a aplicação com herbicida pré-emergente (SC2) e que a testemunha (SC1). A Tabela 1 também revela que os sistemas de controle por meio do pastejo (SC4 e SC5) foram significativamente mais eficientes que os demais métodos de controle da vegetação nativa do

Tabela 1- Disponibilidade total de matéria seca do substrato herbáceo nas entrelinhas e linhas de uma floresta de Eucalyptus saligna Smith., clone 175, logo após a retirada dos animais. ${ }^{1}$

Table 1- Total available dry matter of native herbaceous plants between rows and in rows of an Eucalyptus saligna Smith. forest, clone 175, right after the withdraw of the animals

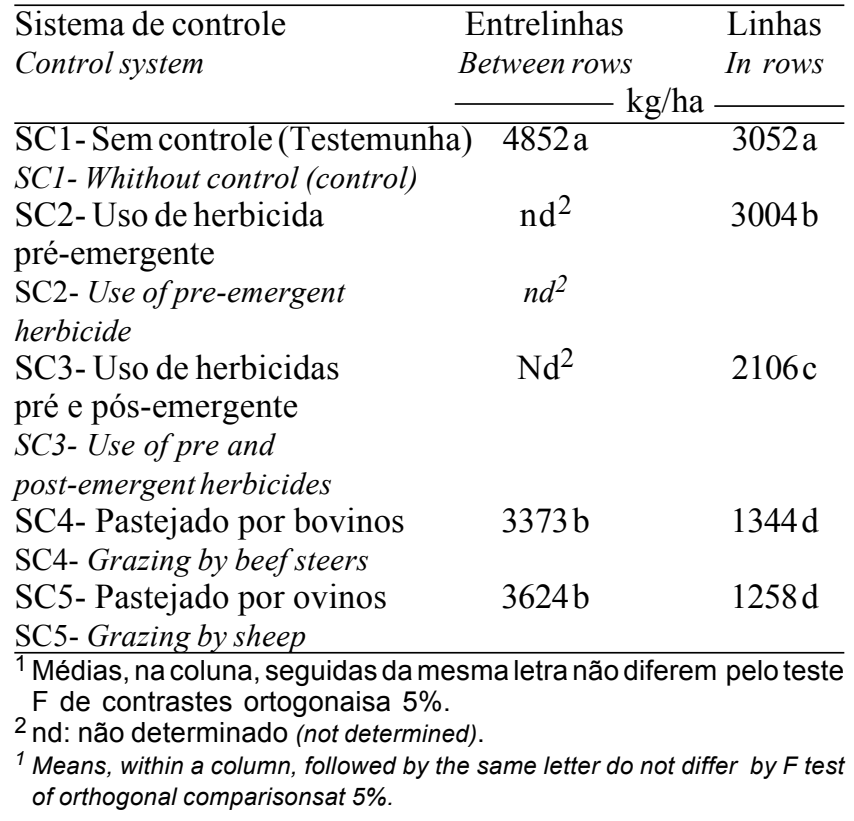

sub-bosque na faixa de plantio. Entretanto, não se verificaram diferenças entre o pastejo com bovinos ou ovinos quanto à DTMS na linha de plantio das árvores. Estes resultados indicam que os bovinos e os ovinos são eficientes agentes controladores da vegetação do sub-bosque, especialmente na faixa de plantio do eucalipto, onde a competição por água e nutrientes é mais intensa no ano do estabelecimento da floresta.

O estudo da utilização de bovinos e ovinos como agentes biológicos de controle da vegetação nativa do sub-bosque também revelou diferenças entre estas duas espécies animais quanto aos danos causados às mudas de eucalipto. A Tabela 2 mostra que os bovinos causaram significativamente maior dano e redução de área foliar (RAF) que os ovinos no ano do estabelecimento de uma floresta de eucalipto. A observação detalhada da Tabela 3 mostra estreita relação entre os danos verificados e a altura das mudas no momento da introdução dos animais na floresta. Os danos mais severos (acima do nível B3) ocorreram em árvores com altura inicial inferior a 182 $\mathrm{cm}$ para os bovinos e $154 \mathrm{~cm}$ para os ovinos. Os danos provocados pelos bovinos, observados mais freqüentemente durante o experimento, foram referentes ao pisoteio de mudas menores e à quebra de ramos laterais médios e superiores do eucalipto, ao se apoiarem sobre as árvores $(\mathrm{B} 3,30)$. Os ovinos causaram danos mais freqüentes ao buscar a sombra das árvores para se proteger do calor, provocando a quebra de ramos laterais inferiores do eucalipto $(\mathrm{B} 1,84)$. Estes comportamentos justificam os níveis médios obtidos para danos causados por bovinos e ovinos nas mudas de eucalipto (Tabela 2). Estes resultados indicam que a utilização de bovinos ou de

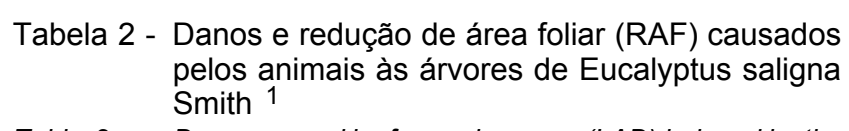

Table 2 - Damages and leaf area decrease (LAD) induced by the animals to the trees of Eucalyptus saligna Smith

\begin{tabular}{|c|c|c|}
\hline Sistema de controle & Danos & RAF \\
\hline \multirow[t]{2}{*}{ Control system } & Damages & $L A D$ \\
\hline & Pontos & $\%$ \\
\hline SC4- Pastejo com bovinos & B330 a & $3835 \mathrm{a}$ \\
\hline SC4- Grazing by beef steers & & \\
\hline SC5- Pastejo com ovinos & $\mathrm{B} 1,84 \mathrm{~b}$ & $8,78 \mathrm{~b}$ \\
\hline SC5- Grazing by sheeps & & \\
\hline \multicolumn{3}{|c|}{$\begin{array}{l}{ }^{1} \text { Médias, na coluna, seguidas da mesma letra não diferem pelo teste } \\
\mathrm{F} \text { de contrastes ortogonaisa } 5 \% \text {. }\end{array}$} \\
\hline $\begin{array}{l}{ }^{1} \text { Means, within a column, followe } \\
\text { of orthogonal comparisonsat } 5 \%\end{array}$ & & \\
\hline
\end{tabular}


ovinos como ferramentas de controle da vegetação nativa do sub-bosque, no ano do estabelecimento de uma floresta de eucalipto, também está vinculada à altura das mudas no momento da introdução dos animais na floresta. Neste sentido, os ovinos apresentam maior eficiência de controle quando se deseja antecipar o pastejo em áreas florestais recém estabelecidas.

Os resultados apresentados na Tabela 3 ainda revelam que a experiência prévia dos animais, introduzidos para pastejo sob uma floresta recém implantada, reduz os danos causados às árvores, conforme já salientaram HAINES et al. (1994). Observa-se na Tabela 3 que os danos e a redução de área foliar (consumo de folhas) médias obtidas na repetição 2 foram superiores aos medidos na repetição 1. Isto indica que o fato de os bovinos ou ovinos iniciarem pastejando a repetição 2 determinou adaptação suficiente dos animais ao ambiente florestal, diminuindo os danos e a RAF na repetição posteriormente pastejada.

Finalmente, não se verificaram efeitos de densidades arbóreas sobre os danos ou sobre o consumo de folhas provocados pelos animais nos eucaliptos. Ao contrário do que se previa, muitos resultados mostraram prejuízos maiores produzidos pelos animais nas densidades arbóreas menores (Tabela 3 ), o que pode ser atribuído ao maior acúmulo de biomassa vegetal nativa de baixa qualidade nutritiva em espaçamentos maiores, em decorrência da maior incidência luminosa no sub-bosque. O acúmulo excessivo de matéria seca no sub-bosque pode ter, inicialmente, estimulado os animais a experimentar o tecido vegetal mais tenro das folhas e dos ramos do eucalipto.

Tabela 3 - Danos, redução de área foliar (RAF) causados por bovinos ou ovinos às árvores e altura das mudas (ALTPRE) em uma floresta de Eucalyptus saligna Smith., clone 175

Table 3 - Damages, leaf area decrease (LAD) induced by beef steers or sheeps to the trees, plant height (PLH) in a Eucalyptus saligna Smith forest, clone 175

\begin{tabular}{|c|c|c|c|c|c|c|c|}
\hline \multirow{4}{*}{$\begin{array}{l}\text { Repetição } \\
\text { Replication }\end{array}$} & \multirow{4}{*}{$\begin{array}{l}\text { Densidade } \\
\text { Population }\end{array}$} & \multicolumn{3}{|c|}{ Bovinos } & \multicolumn{3}{|c|}{ Ovinos } \\
\hline & & \multicolumn{3}{|c|}{ Beef steers } & \multicolumn{3}{|c|}{ Sheeps } \\
\hline & & Danos & RAF & Altpre $^{3}$ & Danos & RAF & Altpre $^{3}$ \\
\hline & & Damages & $L A D$ & PLH & Damages & $L A D$ & PLH \\
\hline & $\mathrm{Pl} / \mathrm{ha}$ & Pontos & $\%$ & $\mathrm{~cm}$ & Pontos & $\%$ & $\mathrm{~cm}$ \\
\hline & Tree/ha & Scores & & & Scores & & \\
\hline \multirow[t]{3}{*}{1} & 816 & B2,40 & 8,30 & 220 & B0,63 & 1,53 & 237 \\
\hline & 400 & B2,85 & 12,35 & 180 & B 1,35 & 2,50 & 193 \\
\hline & 204 & B3,10 & 28,19 & 177 & B 2,00 & 4,90 & 181 \\
\hline \multirow{3}{*}{$\begin{array}{l}\text { Média } \\
\text { Mean }\end{array}$} & & $\mathrm{B} 2,78 \mathrm{a}^{1}$ & $16,28 \mathrm{~A}^{2}$ & 192 & $\mathrm{~B} 1,33 \mathrm{~b}$ & $2,98 \mathrm{~B}$ & 204 \\
\hline & 816 & D 20 & 2120 & 151 & D? & 142 & 154 \\
\hline & 010 & D, 20 & 31,32 & 154 & $B 2, / 0$ & 14,20 & 154 \\
\hline \multirow{2}{*}{2} & 400 & B3,26 & 47,00 & 182 & B 2,20 & 13,75 & 227 \\
\hline & 204 & B4,81 & 97,10 & 157 & B2,19 & 15,81 & 212 \\
\hline Média & & $\mathrm{B} 3,76 \mathrm{a}^{1}$ & $58,47 \mathrm{~A}^{2}$ & 164 & B 2,36b & $14,59 \mathrm{~B}$ & 198 \\
\hline
\end{tabular}

Mean

${ }^{1}$ Médias, na linha, seguidas da mesma letra minúscula são diferentes pelo teste $\mathrm{F}$ de contrastes ortogonais a $5 \%$.

2 Médias, na linha, seguidas da mesma letras maiúscula são diferentes pelo teste $\mathrm{F}$ de contrastes ortogonais a $5 \%$.

${ }^{3}$ Altura média das árvores quando os animais iniciaram o pastejo na área experimental.

${ }^{1}$ Means, within a row, followed by different small letter are different by $\mathrm{F}$ test of orthogonal comparisons at $5 \%$.

${ }^{2}$ Means, within a row, followed by different capital letter are different by $F$ test of orthogonal comparisons at $5 \%$.

${ }^{3}$ Average tree height when animals started grazing the experimental pastures.

\section{Conclusões}

A utilização de bovinos ou ovinos, como agentes controladores da vegetação nativa do sub-bosque, reduz eficientemente a competição inicial sobre as mudas de eucalipto no ano do estabelecimento da floresta.

A altura inicial das mudas, no momento da intro- dução dos animais na área, é fator importante a se considerar em sistemas silvopastoris, visando a diminuição dos danos causados às árvores.

Independentemente das densidades arbóreas, os danos e o consumo de folhas provocados às árvores por bovinos são maiores que os causados pelos ovinos no ano do estabelecimento das mudas de eucalipto. 
34 Rev. bras. zootec.

\section{Agradecimentos}

À empresa florestal Riocell S.A., Guaíba/RS, pela colaboração técnica e financeira, e ao $\mathrm{CNPq}$, pelos recursos oferecidos para a realização deste trabalho.

\section{Referências Bibliográficas}

COUTO, L., ROATH, R.L., BETTERS, D.R. et al. 1994. Cattle and sheep in eucalypt plantations: a silvopastoral alternative in Minas Gerais. Agroforestry Systems, 28(2):173-185.

HAINES, P. J., BELL, A.B., THATCHER, L.P. 1994. Evaluation of some factors involved in reducing browsing damage to eucalypt trees by sheep. Austr. J. Exp. Agric., 34(5):601-607.
POPAY, I., FIELD, R. 1996. Grazing animals as weed control agents. Weed Technology, 10(1):217-231.

VEIGA, J. B., SERRÃO, E. A. S. Sistemas silvopastoris e produção animal nos trópicos úmidos: experiência da Amazônia brasileira. In: REUNIÃO ANUAL DA SOCIEDADE BRASILEIRA DE ZOOTECNIA, 26, Piracicaba, SP, 1990. Anais... Piracicaba: FEALQ, 1990. p. 38-68.

Recebido em: $12 / 02 / 98$

Aceito em: $14 / 08 / 98$ 